\title{
Feature memory and binding in young and older adults
}

\author{
BARBARA L. CHALFONTE and MARCIA K. JOHNSON \\ Princeton University, Princeton, New Jersey
}

\begin{abstract}
Intact memory for complex events requires not only memory for particular features (e.g., item, location, color, size), but also intact cognitive processes for binding the features together. Binding provides the memorial experience that certain features belong together. The experiments presented here were designed to explicate these as potentially separable sources of age-associated changes in complex memory-namely, to investigate the possibility that age-related changes in memory for complex events arise from deficits in (1) memory for the kinds of information that comprise complex memories, (2) the processes necessary for binding this information into complex memories, or (3) both of these components. Young and older adults were presented with colored items located within an array. Relative to young adults, older aduits had a specific and disproportionate deficit in recognition memory for location, but not for item or for color. Also, older adults consistently demonstrated poorer recognition memory for bound information, especially when all features were acquired intentionally. These feature and binding deficits separately contribute to what have been described as older adults' context and source memory impairments.
\end{abstract}

Memories for complex events include multiple kinds of information, such as information that was of central interest to the participant or observer (e.g., semantic features), information about the time or the place at which the central information was acquired, the modality of presentation, a speaker's voice, associated emotions, item parameters such as color and size, and so forth. Research findings suggest that older adults have impaired memory for such kinds of information (see Kausler, 1994, for a review). Simply having intact memory for these various features would not necessarily yield intact complex memories, however. Consider that when recollecting a complex event, we do not remember a jumble of different kinds of information or features. We do not remember blue, brown, pen, table, but rather a blue pen on a brown table. Thus, complex memories not only require memory for particular features, but also certain cognitive processes for binding the features together. Binding provides the memorial experience that certain features belong together. There has been no systematic research to evaluate the possibility that age-related changes in memory for complex events may arise from deficits in (1) memory for the kinds of informa-

This research was supported by National Institute on Aging Grants AG09744 and AG09253. National Institute of Mental Health Grant MH50131, and by a Grant-in-Aid of Research from Sigma Xi, The Scientific Research Society. We also thank Julie Bush, Sarah K. Smith, and Christine Voegeli for their assistance in data collection, and Carolyn Rovee-Collier, Michael Masson, and two anonymous reviewers for their comments on a previous draft. A preliminary version of Experiments 1 and 2 was presented at the Convention of the American Psychological Society, Chicago, June 1993. Correspondence concerning this article should be addressed to B. L. Chalfonte, Department of Psychology, Mount Holyoke College, South Hadley, MA 01075 (e-mail: bchalfon@mhc.mtholyoke.edu). tion that constitute complex memories, (2) the processes necessary for binding this information into complex memories, or (3) both of these components. The experiments presented here were designed to begin to explicate these as potentially separable sources of age-associated changes in complex memory.

Complex-event memories play a central role in everyday life. For example, the information included in such memories is crucial for a sense of autobiography. If we are to have a sense of remembering a specific instance from our own experiences, our memories must include sourcespecifying information (e.g., Johnson, Hashtroudi, \& Lindsay, 1993; Johnson \& Raye, 1981). Source-specifying information includes a variety of features (e.g., spatial or temporal information, the modality of presentation, cognitive operations information) that describe the conditions under which the memory was acquired (Johnson et al., 1993). If feature information, such as location, color, or size, is available, then judgments about the source of the memory are more likely to be accurate. For instance, knowing the location on a page of an article about tennis can support the recollection that the tennis story was read in the morning newspaper and not in a magazine, or knowing the color of a sweater that a colleague wore can serve as a reminder that one has discussed an interesting research idea with her.

Evidence suggests that older adults have some impairment remembering source-specifying features such as location and color. Consider comparisons in young and older adults' memory for location, for example. Light and Zelinski (1983) found that older adults' memory for the location of structures on a map was poorer than young adults', when location information was acquired either incidentally or intentionally. Pezdek (1983) noted that older adults' 
memory for the location of 16 pictured objects or their corresponding verbal labels within a $6 \times 6$ array was poorer than that of young adults. Park, Puglisi, and Sovacool (1983) similarly found that older adults' memory for the quadrant in which pictures or words had appeared was poorer under both incidental and intentional encoding conditions. These data seem to converge on the notion that older adults have impaired memory for location, and poor memory for location may represent only one facet of a more extensive impairment in remembering the many features that are important for specifying the source of memories (e.g., Spencer \& Raz, 1995).

In the studies documenting older adults' relatively poorer location memory (Light \& Zelinski, 1983; Park et al., 1983; Pezdek, 1983), in addition to having poor location memory, older adults also had poorer memory for the items being tested (e.g., structures, pictures, words). The finding that they also had poorer memory for the items argues against the idea that older adults have a special impairment in memory for source-specifying information. Only if older adults' impairment in memory for source information is disproportionate relative to memory for some other kind of information (e.g., item) is the proposition compelling. One step in determining whether older adults have a disproportionate impairment in memory for the kind of information that specifies when and how information is acquired is to equate item memory between young and older adults and then determine whether source information is disproportionately impaired (see, e.g., Ferguson, Hashtroudi, \& Johnson, 1992).

Furthermore, when one compares memory for items and memory for the items' source, it is crucial to test memory for these two aspects in the same way. Unless the items and source features are assessed with the same type of test, any differences observed may be a consequence of the type of test rather than of any age-related change in memory for the source features in question. Often, memory for items (pictures or words) is evaluated with a yes/no or forced-choice recognition test and memory for source features is evaluated with a cued recall test. For example, recognition memory for a word might be accompanied by a cued recall test of memory for the voice in which the word was spoken (e.g., Ferguson et al., 1992; Kausler \& Puckett, 1981). Or, memory for location might be evaluated by presenting an item in a neutral location and asking subjects to recall its prior location (e.g., Light \& Zelinski, 1983; Park, Puglisi, \& Lutz, 1982; Park et al., 1983; Zelinski \& Light, 1988). Although it is common, testing item memory by using recognition and testing source memory by using cued recall may confound conclusions about the precise changes that occur with age, especially when the aspect of interest, source, is tested with cued recall. Evidence suggests that cued recall is generally more difficult than recognition, especially for older adults (Craik, 1977; Craik \& McDowd, 1987; Light $\&$ LaVoie, 1993). In order to more fairly evaluate agerelated changes in memory for source in comparison with memory for items, item memory and source memory must be evaluated with the same kind of test.
Another common method of investigating older adults' ability to recollect source-specifying features is to assess memory for the source features in the presence of the corresponding item information, or assess source features only when there is evidence of memory for the item. If a subject is asked to recollect the location of a particular item, for example, correct performance requires not only memory for the location that was filled, but also memory for which item filled the particular location. Correct recollection of an item's location therefore requires (1) intact memory for item features (i.e., which items were seen) and location features (i.e., which locations were filled), and (2) intact processes that bind together item and location information (this location was filled by this item). Other researchers have also distinguished between recognition memory for items (included in our use of the term features) and the association between items (included in our use of the term binding) (e.g., Gronlund \& Ratcliff, 1989; Humphreys, 1976, 1978). If memory for a complex event requires both memory for item and source features and binding between item and source features, then older adults' impaired memory might be due to impaired memory for the features themselves (a feature deficit) and/or disrupted binding between the features (a binding deficit).

We were interested in determining whether there were separable, age-related contributions of feature and binding deficits to older adults' impaired memory for complex events. Moreover, we were interested in determining whether features that are often important for determining the source of memories are disproportionately affected by aging. Disproportionately impaired memory for non-item features could in turn contribute to impairments in older adults' ability to make source monitoring decisions (Ferguson et al., 1992; Hashtroudi, Johnson, \& Chrosniak, 1989; Hashtroudi, Johnson, Vnek, \& Ferguson, 1994; Schacter, Kasniak, Kihlstrom, \& Valdiserri, 1991). In the experiments that follow, we separately assessed potential age-related deficits in the ability to bind features into complex memories and in memory for the features that constitute these complex events. To do this, we directed young and older subjects to study specific aspects of 30 colored objects located within a $7 \times 7$ array (see Figure 1). Using recognition tests exclusively, we then assessed (1) whether memory for individual source features such as location and color were disproportionately impaired relative to memory for items, and (2) subjects' ability to bind together items and other features.

\section{EXPERIMENTS 1A-1B}

\section{Method}

Experiments $1 \mathrm{~A}$ and $\mathrm{IB}$ included conditions that permitted us to compare young and older adults' memory for individual features, specifically item, location, and color, as well as their memory for bound item and location and bound item and color. To evaluate feature memory, in Experiment $1 \mathrm{~A}$, independent groups of subjects saw several colored objects randomly assigned to locations within an array and were instructed to study item only, location only, or color only; the subjects were then tested on their 


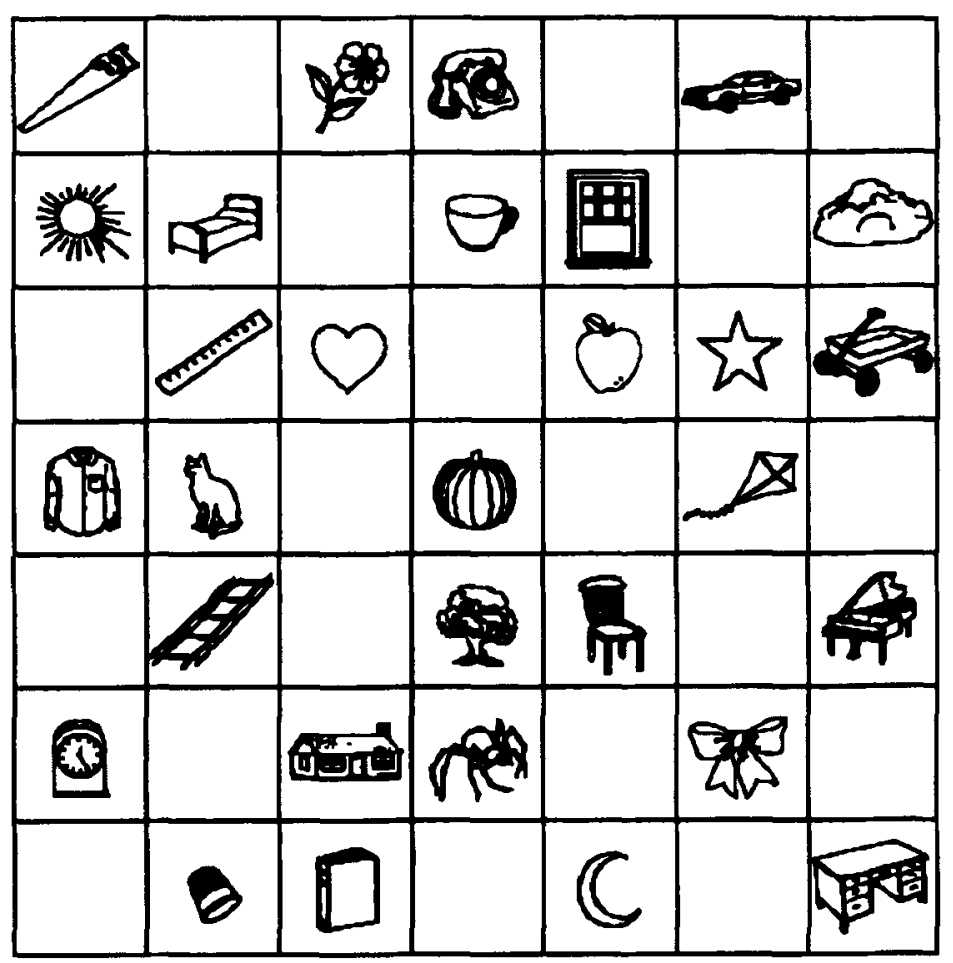

Figure 1. Example study array. Black lines composing the items seen here were colored in the actual arrays.

recognition memory for the feature they had been directed to study. The subjects in Experiment $1 \mathrm{~B}$ were directed to study either item \& location or item \& color and were then tested on their recognition memory for the bound features. In both experiments, all information was acquired under intentional encoding conditions. These experiments were run concurrently.

Subjects. As in all of the experiments reported here, the young adults were undergraduates at Princeton University and the older adults were recruited from local retirement communities; all received payment for the single testing session. The subjects reported being in good health and had normal or corrected-tonormal vision and hearing; none reported any color deficiencies. In Experiment $1 \mathrm{~A}, 48$ young and 48 older adults participated. The mean age of the young adults was 19.2 years $(S D=1.4)$, and the mean age of the older adults was 70.5 years $(S D=4.6)$. The mean WAIS-R vocabulary score for the last 15 items (maximum score $=30)$ was $21.7(S D=5.3)$ for the older adults. ${ }^{1}$ The mean number of years of education was $13.9(S D=1.2)$ for the young adults and $15.1(S D=2.3$ ) for the older adults; a 2 (age) $\times 3$ (feature instruction condition) analysis of variance (ANOVA) on years of education showed that there was a reliable effect of age $\left[F(1,90)=10.42, M S_{\mathrm{e}}=3.48, p<.01\right]$, but no effect of condition nor interaction $\left[F_{\mathrm{S}}(2,90)<1\right]$. In Experiment $1 \mathrm{~B}$, the 32 young and 32 older adults had a mean age of 19.1 years $(S D=1.3)$ and 69.5 years $(S D=4.6)$, respectively. The older adults' mean WAIS-R vocabulary score was $19.2(S D=4.6)$. The mean number of years of education was $13.7(S D=1.0)$ for the young adults and $14.8(S D=2.3)$ for the older adults; a 2 (age) $\times 2$ (binding instruction condition) ANOVA on years of education showed that there was a reliable effect of age $\left[F(1,60)=5.95, M S_{\mathrm{e}}=3.04, p<\right.$ $.05]$, but no effect of condition $[F(1,60)=2.49]$, nor interaction $[F(1,60)=1.67]$. There were 16 young and 16 older subjects in each of the conditions of both experiments.

Study materials. The study array consisted of a two-dimensional $19 \times 19 \mathrm{~cm}$ grid representing 49 locations in seven rows and seven columns. Thirty drawings of common objects (Snodgrass \& Vanderwart, 1980) were assigned randomly to locations with the restriction that no more than five objects be placed in any given row or column. Each item was also randomly assigned a unique color - the lines composing the object were colored and the interior was white (RGB components defining each color are listed in the Appendix). Colors that were naturally associated with particular objects were avoided (e.g., a leaf might appear in a shade of pink, but not in a shade of green or brown). Two such arrays were generated. ${ }^{2}$ An example of the array is seen in Figure 1 .

Test materials. Examples of the recognition tests are shown in Figure 2. In Experiment $1 A$, for the item-only recognition test, 10 items that were in the array as well as 10 new items were arranged in five rows with 4 items each (without grid lines); the items were black and white only. The subjects were instructed to indicate items that had appeared anywhere in the original array. The locationonly recognition test consisted of a $7 \times 7$ array with a black " $X$ " in each of 10 locations that had been filled previously in the studied array and 10 locations that had not been filled in the original array. The subjects were instructed to indicate Xs occupying locations that had previously been filled. The color-only test consisted of five rows of 4 color blocks. A block was a rectangular outline with 12 diagonal lines within it; all of the lines were colored. Ten of the blocks were the same color as 10 items in the studied array while the other 10 blocks had new colors. The subjects indicated color blocks corresponding to colors that had appeared in the previous array. For Experiment $1 \mathrm{~B}$, the item \& location recognition test consisted of a $7 \times 7$ array with 10 black-and-white items from the original array in their original locations, 5 items from the array in new locations, and 5 new items in previously filled locations. The subjects were instructed to indicate an item only if both the item and its location corresponded to that in the previous array. The item \& color recognition test consisted of five rows of 4 colored items (without grid lines). Ten items were the same color as 


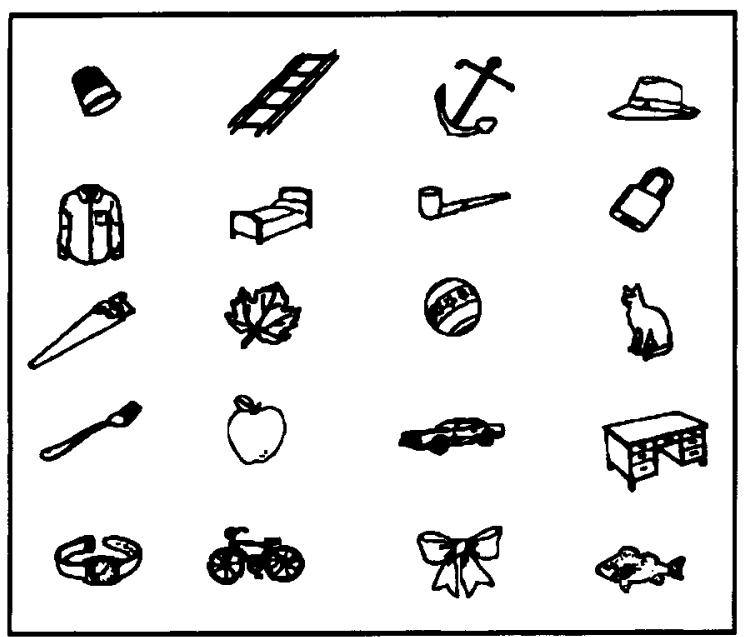

(a)

\begin{tabular}{|l|l|l|l|l|l|l|}
\hline & $\mathrm{X}$ & $\mathrm{X}$ & & & & $\mathrm{X}$ \\
\hline & & $\mathbf{X}$ & & $\mathbf{X}$ & $\mathrm{X}$ & \\
\hline $\mathbf{X}$ & $\mathrm{X}$ & & & & $\mathrm{X}$ & \\
\hline & & $\mathbf{X}$ & & $\mathbf{X}$ & $\mathbf{X}$ & \\
\hline $\mathbf{X}$ & & & $\mathbf{X}$ & & & $\mathbf{X}$ \\
\hline $\mathbf{X}$ & & $\mathbf{X}$ & & $\mathbf{X}$ & & \\
\hline & & & & $\mathbf{X}$ & $\mathbf{X}$ & \\
\hline
\end{tabular}

\section{$\mathbb{Z M} \mathbb{Z M}$ \\ $\mathbb{M} \mathbb{M} \mathbb{M}$ \\ $\mathbb{Z M} \mathbb{Z M}$ \\ $\mathbb{M} \mathbb{\mathscr { M }} \mathbb{\mathscr { M }}$ \\ $\mathbb{M} \mathbb{M} \mathbb{Z}$}

(c)

\begin{tabular}{|c|c|c|c|c|c|c|}
\hline$\infty$ & & 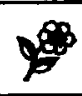 & & & W & \\
\hline 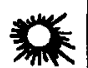 & 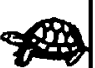 & & $\theta$ & & & $\sin$ \\
\hline & & $\hat{\beta}^{B}$ & (11) & & (1) & \\
\hline $\overrightarrow{\theta \rightarrow C O}$ & & $\hat{\zeta}$ & & $\vec{\pi}$ & & \\
\hline & & & Rी & & & 8 \\
\hline & 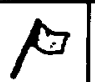 & & & & $\mathbb{R S}$ & \\
\hline
\end{tabular}

(d)

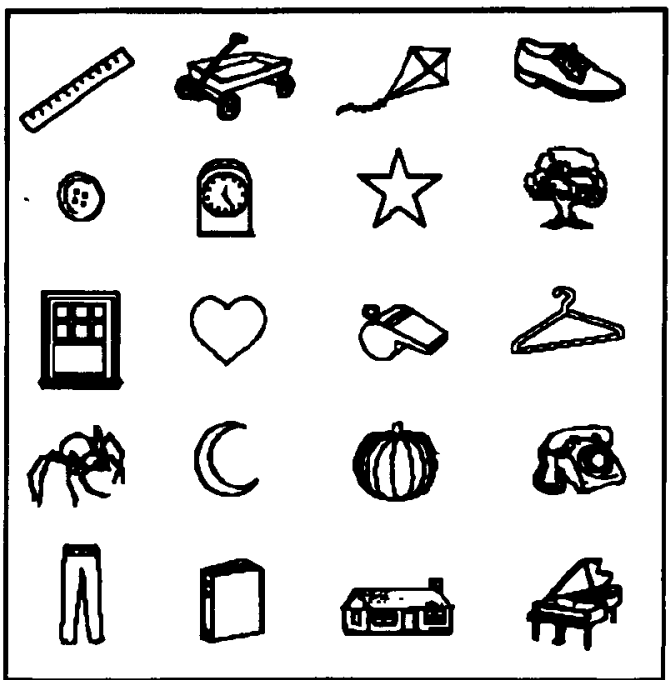

(e)

Figure 2. Example recognition tests. (a) Item only. (b) Location only. (c) Color only-black lines composing the color blocks seen here were colored in the actual tests. (d) Item \& location. (e) Item \& color-black lines composing the items seen here were colored in the actual tests. 
they were in the studied array, 5 items from the array were newly colored, and 5 new items were colored with colors used in the original array. As for the targets, colors that were naturally associated with the items were avoided in the construction of the distractors. The subjects were instructed to indicate an item only if both the item and its color corresponded to that in the previous array. Two sets of these recognition tests were constructed.

Procedure. Half of the subjects in each condition received materials from Set 1 , and the other half, from Set 2 . For each condition, the subjects were instructed which feature(s) to study and were then presented with the study array for $90 \mathrm{sec}$. Instructions described not only the feature(s) that they should study, but also the recognition test for the same feature(s); thus, the subjects were fully informed about the nature of the upcoming test. Immediately following the acquisition phase, the subjects were instructed about the nature of the recognition test and then had $90 \mathrm{sec}$ to complete it. Some researchers of older adults' feature memory have found that when the time for study and/or test is open-ended, older adults may take more time than do young adults (Light \& Zelinski, 1983; Perlmutter, Metzger, Nezworski, \& Miller, 1981). Here we constrained both study and test times in order to assess memory in young and older adults under identical conditions.

\section{Results and Discussion}

Table 1 shows the proportion of hits (targets selected), false alarms (distractors selected), corrected recognition scores (proportion hits minus false alarms), and $A^{\prime}$ scores (Donaldson, 1992) for the conditions in Experiments lA and $\mathrm{IB}$ as well as for the other experiments. As can be seen in Table 1, the pattern of corrected recognition scores is consistent with that of $A^{\prime}$ scores. Thus, for simplicity, we present only the analyses of corrected recognition. ${ }^{3}$ Mean corrected recognition scores and their standard errors are shown in Figures 3 and 4 . Note that if the lower part of the standard error bar is visibly above the line indicating $0 \%$ corrected recognition performance, the group's average corrected recognition was reliably better than chance performance. The significance level was set at .05 for all of the statistical analyses reported here unless otherwise specified. All comparisons were planned.

For the individual feature conditions of Experiment $1 \mathrm{~A}$ (see Figure 3), we first evaluated whether the perfor- mance of the young adult subjects was different from that of the older adult subjects in the item recognition condition; this is a crucial first step in determining whether memory for non-item features is disproportionately affected by age. Item memory did not significantly differ between young $(M=.91)$ and older adults $(M=$ .89) $[F(1,30)<1]$. Given that memory for items was not different between young and older adults, any observed impairment in memory for location or for color in older adults indicates a disproportionate effect of age on memory performance for these features. A 2 (age) $\times 2$ (feature condition) ANOVA on young and older adults' corrected recognition performance for non-item features showed a main effect of age $\left[F(1,60)=7.43, M S_{\mathrm{e}}=.05\right]$, no effect of condition $[F(1,60)<1]$, and a significant interaction $[F(1,60)=5.12]$. This interaction was clarified by planned comparisons for each of the non-item feature conditions: There was no significant age difference in recognition memory for color $\left(M_{\text {young }}=.24\right.$; $\left.M_{\text {older }}=.21\right)[F(1,30)<1]$, whereas memory for location was significantly poorer in older adults $(M=.07)$ than in young subjects $(M=.34)\left[F(1,30)=10.13, M S_{\mathrm{e}}=\right.$ $.06]$. Indeed, older adults' memory for location was not different from chance performance. This pattern of performance suggests that older adults do not have a general deficit in memory for all features, but rather have a specific and disproportionate deficit in memory for location information. This is not to say that older adults might not have impaired memory for other features; rather, the finding that recognition memory for items and for colors is intact (under the study/test conditions used here) rules out the possibility that recognition memory for all features is impaired under the present conditions.

Of possible concern is the difference in absolute levels of performance on the three feature recognition tests; item recognition performance was high $(M=.90)$, whereas corrected recognition of location $(M=.20)$ and of color $(M=.23)$ was much lower. As Chapman and Chapman (1973) have noted, when the difficulty of tests

Table 1

Recognition Performance of Young and Older Adults in Experiments 1-3

\begin{tabular}{|c|c|c|c|c|c|c|c|c|c|c|c|c|c|c|c|c|c|}
\hline \multirow[b]{3}{*}{ Experiment } & \multirow{3}{*}{$\begin{array}{l}\text { Study/Test } \\
\text { Condition }\end{array}$} & \multicolumn{8}{|c|}{ Young } & \multicolumn{8}{|c|}{ Older } \\
\hline & & \multicolumn{2}{|c|}{ Hits } & \multicolumn{2}{|c|}{ FAs } & \multicolumn{2}{|c|}{ CR } & \multicolumn{2}{|c|}{$A^{\prime}$} & \multicolumn{2}{|c|}{ Hits } & \multicolumn{2}{|c|}{ FAs } & \multicolumn{2}{|c|}{ CR } & \multicolumn{2}{|c|}{$A^{\prime}$} \\
\hline & & $M$ & $S E$ & $M$ & $S E$ & $M$ & $S E$ & $M$ & $S E$ & $M$ & $S E$ & $M$ & $S E$ & $M$ & $S E$ & $M$ & $S E$ \\
\hline \multirow[t]{3}{*}{$\mathrm{IA}$} & $\mathrm{I} / \mathrm{I}$ & .93 & .03 & .02 & .01 & .91 & .03 & .98 & .01 & .95 & .02 & .06 & .02 & .89 & .04 & .97 & .01 \\
\hline & $\mathrm{L} / \mathrm{L}$ & .58 & .06 & .24 & .03 & .34 & .07 & .72 & .05 & .56 & .05 & .49 & .04 & .07 & .05 & .54 & .05 \\
\hline & $\mathrm{C} / \mathrm{C}$ & .65 & .05 & .41 & .04 & .24 & .05 & .68 & .05 & .71 & .05 & .50 & .05 & .21 & .04 & .67 & .04 \\
\hline $1 B$ & $\mathrm{IL} / \mathrm{IL}$ & .71 & .05 & .05 & .02 & .66 & .06 & .90 & .02 & .64 & .05 & .06 & .02 & .58 & .05 & .88 & .02 \\
\hline \multirow[t]{2}{*}{2} & $\mathrm{I} / \mathrm{IC}$ & .59 & .05 & .08 & .03 & .51 & .05 & .85 & .02 & .64 & .06 & .19 & .04 & .45 & .06 & .80 & .04 \\
\hline & $\mathrm{C} / \mathrm{IC}$ & .66 & .05 & .16 & .03 & .49 & .06 & .83 & .03 & .58 & .05 & .25 & .04 & .33 & .05 & .75 & .03 \\
\hline \multirow[t]{2}{*}{$3 \mathrm{~A}$} & $\mathrm{I} / \mathrm{I}$ & .93 & .02 & .03 & .01 & .91 & .02 & .98 & .01 & .92 & .02 & .01 & .01 & .91 & .02 & .98 & .01 \\
\hline & $\mathrm{C} / \mathrm{C}$ & .69 & .05 & .47 & .04 & .23 & .07 & .64 & .07 & .81 & .05 & .59 & .06 & .23 & .04 & .74 & .02 \\
\hline \multirow[t]{2}{*}{$3 \mathrm{~B}$} & $\mathrm{~V} / \mathrm{IC}$ & .54 & .04 & .18 & .03 & .36 & .06 & .75 & .04 & .56 & .07 & .25 & .04 & .31 & .05 & .74 & .03 \\
\hline & $\mathrm{IC} / \mathrm{IC}$ & .77 & .03 & .05 & .02 & .72 & .03 & .93 & .01 & .53 & .06 & .10 & .02 & .43 & .07 & .81 & .03 \\
\hline
\end{tabular}

Note-FAs, false alarms; CR, corrected recognition, difference between proportion of hits and false alarms: I, item; L, location; C, color; IL, item \& location; IC, item \& color. $A^{\prime}$ of 1.0 indicates maximal performance and $A^{\prime}$ of .5 indicates chance performance. 


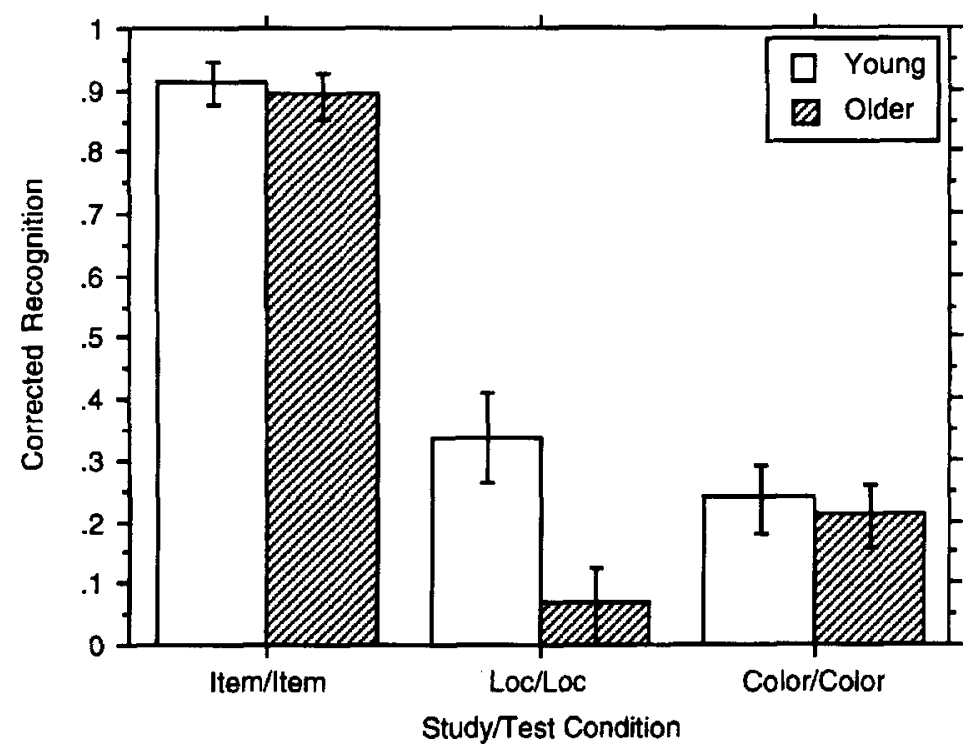

Figure 3. Mean corrected recognition performance and standard errors in Experiment $1 \mathrm{~A}$ feature conditions.

varies, artifactual interactions between task performance and subject type can arise. However, we point out that location and color recognition performances were similar in young adults, and that older adults were impaired only on the location recognition test, not on the color recognition test.

These data are consistent with, for example, Perlmutter et al.'s (1981) comparison of memory for location and memory for temporal information in young and older adults. They found a deficit in older adults' memory for spatial information but not temporal information. In Perlmutter et al.'s study, memory for location information was evaluated by asking subjects to recall the locations of distinctive buildings on a map that they had studied previously. Memory for temporal information was evaluated by sequentially presenting pictures of common objects; interspersed were test probes in which two previously seen pictures were presented, and the subjects' task was to indicate which picture had been presented more recently. Conclusions from Perlmutter et al.'s data must be qualified, however, because (1) it is unclear whether memory for location and temporal features was disproportionately impaired relative to memory for objects, and (2) memory for individual object, location, and temporal features was not evaluated; location and temporal features were encoded and tested only in the presence of their corresponding items.

Other research focusing exclusively on location memory in young and older adults also documents a deficit similar to the one seen here (e.g., Light \& Zelinski, 1983; Naveh-Benjamin, 1987, 1988; Park, Cherry, Smith, \& Lafronza, 1990; Park et al., 1982; Park et al., 1983; Pezdek, 1983; Schear \& Nebes, 1980; Zelinski \& Light, 1988). To these previous studies, Experiment $1 \mathrm{~A}$ adds evidence of an age-related disproportionate deficit in memory specifically for the feature of location, inde- pendent of associated item information, relative to feature memory for items and for colors. Although older adults have a specific and disproportionate deficit in memory for location feature information, their recognition memory for item and for color feature information was equivalent to that of young adults.

To have intact memory for complex events, not only must memory for the features be available, but the processes important for binding features together must remain unaffected by age. In Experiment 1B, we determined whether there were age-related changes by using conditions in which subjects were required to study and recollect items and locations or items and colors (see Figure 4).

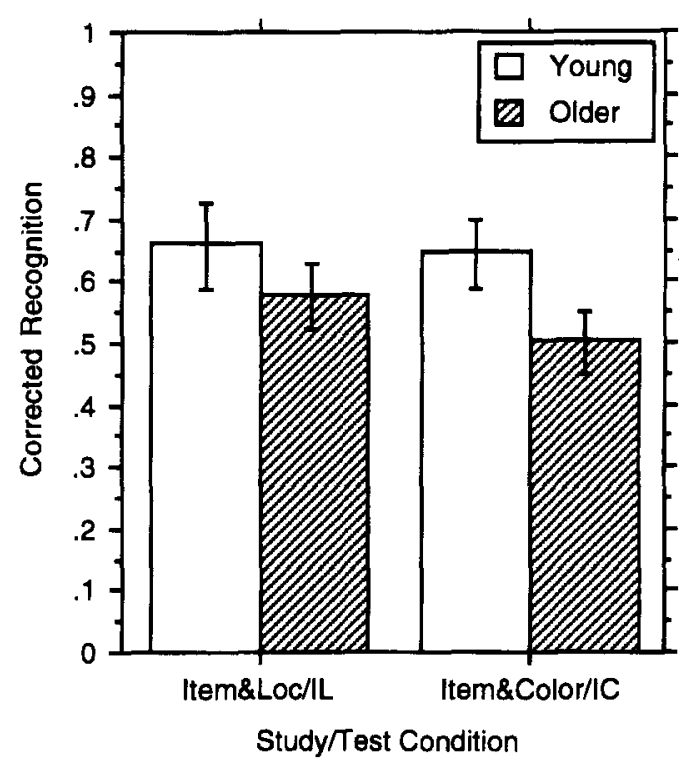

Figure 4. Mean corrected recognition performance and standard errors in Experiment $1 \mathrm{~B}$ binding conditions. 
A 2 (age) $\times 2$ (binding condition) ANOVA on corrected recognition demonstrated that when subjects were directed to study both features, older adults' corrected recognition memory for these bound features $(M=.54)$ was poorer than that of young adults $(M=.66)[F(1,60)=$ $\left.4.62, M S_{\mathrm{e}}=.04\right]$. However, there was no effect of condition, nor was there an interaction between age and condition $[F \mathrm{~s}(1,60)<1]$, suggesting that older adults are less able to bind together features regardless of the features being studied. Older adults have a deficit in memory for location features (refer to Figure 3) that may have contributed to their apparent deficit in memory for bound features, given that one of the features tested was location. Nonetheless, for the data in Figure 4, there was no interaction between age and condition as would be expected if older adults had more difficulty in binding item and location information than in binding item and color information. For this reason, we suspect that the observed deficit in binding lies in the ability to bind information together, and not in memory for the particular features. In short, Experiment $1 \mathrm{~B}$ suggests that older adults may have an impairment in their ability to bind information into complex memories.

\section{EXPERIMENT 2}

\section{Method}

To further clarify the deficit in binding with age, in Experiment 2, we investigated young and oider adults' ability to bind item and color features that were incidentally encoded. We looked at memory for items and color, because intentional memory for these individual features was found in Experiment 1 to be intact in older adults (see Figure 3). Typically, investigators ask whether subjects can incidentally acquire feature information when items are intentionally studied. Here we also asked the complementary question-whether item information can be incidentally acquired when a feature-color-is intentionally studied.

Subjects. Thirty-two college-aged adults and 32 older adults participated in this experiment; none had participated in Experiments $1 \mathrm{~A}$ or $1 \mathrm{~B}$. The mean age of the young adults was 19.4 years $(S D=1.0)$, and the mean age of the older adults was 71.0 years $(S D=4.3)$. The mean WAIS-R vocabulary score for the last 15 items (maximum score $=30)$ was $20.6(S D=6.2)$ for the older adults. The mean number of years of education was $14.0(S D=$ $1.0)$ for the young adults and $14.6(S D=2.2)$ for the older adults; a 2 (age) $\times 2$ (binding instruction condition) ANOVA on years of education showed that there were no reliable effects of age $\left[F(1,60)=2.67, M S_{\mathrm{c}}=3.04\right]$ or condition $[F(1,60)<1]$, nor was there an interaction $[F(1,60)<1$, all $p s>10]$. There were 16 young and 16 older subjects per condition.

Materials and Procedure. The study and test materials and general procedure in this experiment were the same as those in Experiments $1 \mathrm{~A}$ and $1 \mathrm{~B}$. The subjects were instructed to study either item only or color only. Rather than a recognition test for only the studied feature following the study phase as in Experiments $\mathrm{IA}$ and $\mathrm{IB}$, all subjects received an item \& color recognition test.

\section{Results and Discussion}

Mean corrected recognition performance and standard errors for the two binding test conditions after incidental encoding are depicted in Figure 5. A 2 (age) $\times 2$ (binding condition) ANOVA on corrected recognition demonstrated a strong trend in the main effect of age $[F(1,60)=$ $\left.3.71, M S_{\mathrm{e}}=.49, p<.06\right]$, suggesting that older adults $(M=.39)$ have difficulty binding features relative to young adults $(M=.50)$. There was no main effect of condition $[F(1,60)=1.55]$, and the interaction between age and condition did not reach significance $[F(1,60)<1]$; thus, older adults' memory for bound item and color information was not differentially affected by studying either item or color features alone.

On the basis of the results of Experiment 1A, intentional memory for both features-item and color-was known to be intact in older adults. Despite having intact memory for the individual item and color features, in this experiment, older adults again showed somewhat impaired memory for the bound information. These findings, in conjunction with the results of Experiment 1B, suggest that older adults may have a general impairment in their ability to bind information, whether they encode feature information intentionally or incidentally. Moreover, this deficit in binding can occur even for individual features that can be intentionally acquired by older adults without difficulty.

\section{EXPERIMENTS 3A-3B}

\section{Method}

There were three general goals for Experiments $3 \mathrm{~A}$ and $3 \mathrm{~B}$. In Experiment $3 \mathrm{~A}$, the goal was to corroborate the finding of intact item feature memory and color feature memory in older adults that was noted in Experiment 1A. With Experiment 3B, we compared memory for bound item and color information when both features were acquired intentionally and when color was acquired incidentally. Experiment IB suggested that memory for bound feature information that was encoded intentionally is disrupted with age, and Experiment 2 suggested the same for incidentally encoded feature information. However, these previous experiments did not ask whether there is any benefit of encoding information intentionally rather than incidentally, and if so, whether there are any age-related changes associated with such a benefit. Perhaps age-

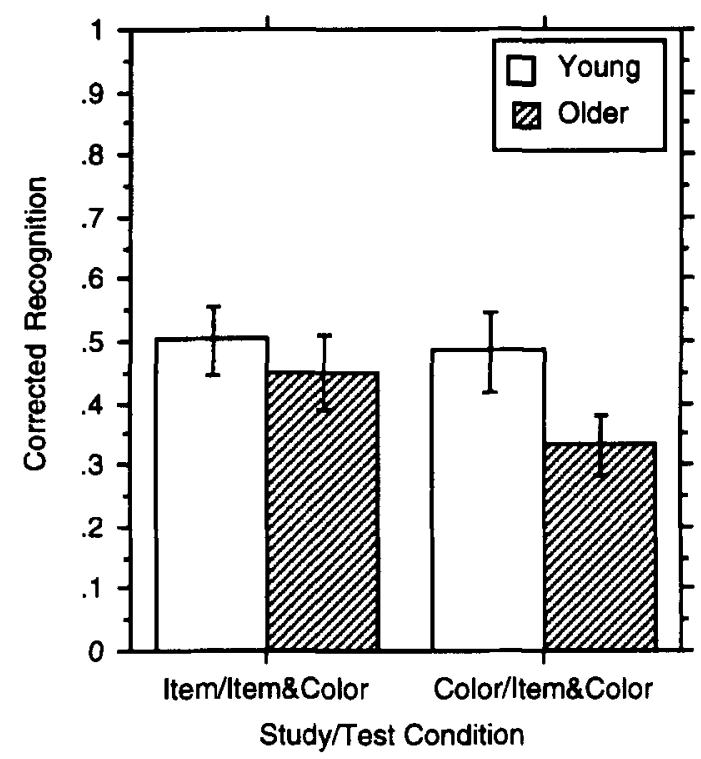

Figure 5. Mean corrected recognition performance and standard errors in Experiment 2 binding conditions. 
related changes in memory for bound information are greater following intentional encoding than following incidental encoding. For example, comparing across Experiments $1 \mathrm{~B}$ and 2, older adults showed relatively more impaired memory for bound item and color when they studied both features (Experiment 1B) than when they studied just the items (Experiment 2). The incidental and intentional encoding conditions in Experiment $3 \mathrm{~B}$ address our second goal, to determine whether older adults, relative to young adults, have memory for bound information that is more impaired when acquisition is intentional than when it is incidental. The incidental and intentional item and color study conditions will also indicate whether color information is acquired automatically by young and/or older adults. If color information is automatically encoded when subjects study its corresponding item information, then intentionally encoding colors with items should result in memory for items and colors that is no better than when colors are incidentally encoded, following Hasher and Zacks's (1979) argument for the automatic encoding of location information.

Our third goal was to construct a recognition test that provided a more stringent test of binding. In the previous experiments, recognition targets comprised two features that were seen together in the studied array. Recognition distractors, in contrast, comprised one old feature seen in the studied array, paired with one new feature. If subjects could discriminate two old features (targets) from one old feature (distractors), theoretically they could perform fairly well on the recognition test even if they had a binding deficit. In Experiment 3, both targets and distractors comprised two old features. Targets were made up of items and colors that were paired as they were in the array; distractors were made up of items and colors from the array that were mispaired. In this case, a binding deficit would have to yield poorer performance on this recognition test, because, even with intact memory for features, targets and distractors are both made up completely of old features and are therefore impossible to distinguish by feature information alone. In short, this new recognition test should provide a more stringent evaluation of memory for bound information.

To summarize, in Experiment $3 \mathrm{~A}$, we assessed memory for item and for color features, expecting to replicate older adults' intact memory for items and for colors using the same encoding conditions as in Experiment 1A. In Experiment 3B, subjects were directed to study either item-only (incidental color) or item \& color (intentional color) and were then tested on their recognition memory for bound item and color using the new recognition tests. Experiments $3 \mathrm{~A}$ and $3 \mathrm{~B}$ were run concurrently.

Subjects. None of the subjects participating in either experiment had participated in any of the previous experiments. In Experiment $3 \mathrm{~A}$, there were 32 young and 32 older adults. The mean age of the young adults was 19.9 years $(S D=0.9)$, and the mean age of the older adults was 71.9 years $(S D=5.6)$. The mean WAIS-R vocabulary score was $21.8(S D=3.9)$ for the young adults and $20.9(S D=5.9)$ for the older adults. The mean number of years of education was $15.0(S D=0.9)$ for the young adults and $15.3(S D=2.4)$ for the older adults; a 2 (age) $\times 2$ (feature instruction condition) ANOVA on years of education showed that there was no main effect of age $[F(1,60)<1]$ or of condition $[F(1,60)=$ $\left.1.19, M S_{\mathrm{e}}=3.37, p>.10\right]$, and no interaction $[F(1,60)<1]$. In Experiment $3 B$, the 32 young and 32 older adults had a mean age of 19.7 years $(S D=1.3)$ and 70.7 years $(S D=5.9)$ respectively. The mean WAIS-R vocabulary score was $21.5(S D=4.4)$ for the young adults and $20.4(S D=6.1)$ for the older adults. The mean number of years of education was $14.7(S D=1.1)$ for the young adults and $14.4(S D=2.0)$ for the older adults; a 2 (age) $\times 2$ (binding instruction condition) ANOVA on years of education showed no effect of age or of condition and no interaction [all $F$ s $(1,59)<1]$. There were 16 young and 16 older subjects in each condition of both experiments.

Materials and Procedure. The study materials and general procedure were the same as those in Experiments 1 and 2. The item
\& color recognition test differed from previous recognition tests only in the construction of the distractors. Rather than having 5 distractors composed of old items and new colors and 5 distractors of new items and old colors, all 10 distractors were composed of old items and old colors that were mispaired relative to their pairings in the studied array. In Experiment $3 \mathrm{~A}$, subjects were instructed to study either items only or colors only and were tested on their recognition memory for the feature that they were directed to study. In Experiment 3B, subjects were instructed to study either items only or items \& colors. All subjects then received the new version of the item \& color recognition tests; as in the other experiments, there were two versions of the recognition tests corresponding to the two versions of the array.

\section{Results and Discussion}

Mean corrected recognition performance and the standard errors are shown in Figures 6 and 7. For the two individual feature conditions of Experiment $3 \mathrm{~A}$ (see Figure 6), item memory did not differ between young ( $M=$ $.91)$ and older adults $(M=.91)[F(1,30)<1]$. Given equivalent item memory performance in young and older adults, any observed impairment in color memory performance would indicate a disproportionate effect of age on memory for this feature. Memory for color, however, was no different in older adults $(M=.23)$ than in young subjects $(M=.23)[F(1,30)<1]$. These results corroborate previous data from Experiment $1 \mathrm{~A}$ that also showed that older adults had equivalent feature memory both for item and for color.

Next we compared young and older adults' corrected recognition memory in Experiment 3B for bound item and color information when they studied both features intentionally and when they studied only item information intentionally (see Figure 7). Recollect that the ability to discriminate targets from distractors on this recognition test required memory for the particular features bound together in the studied array; the ability to sepa-

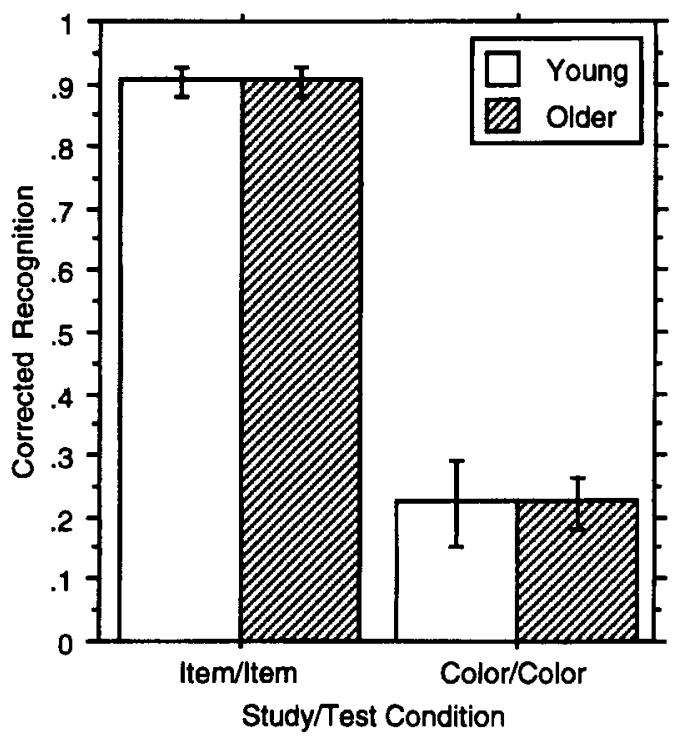

Figure 6. Mean corrected recognition performance and standard errors in Experiment 3A feature conditions. 


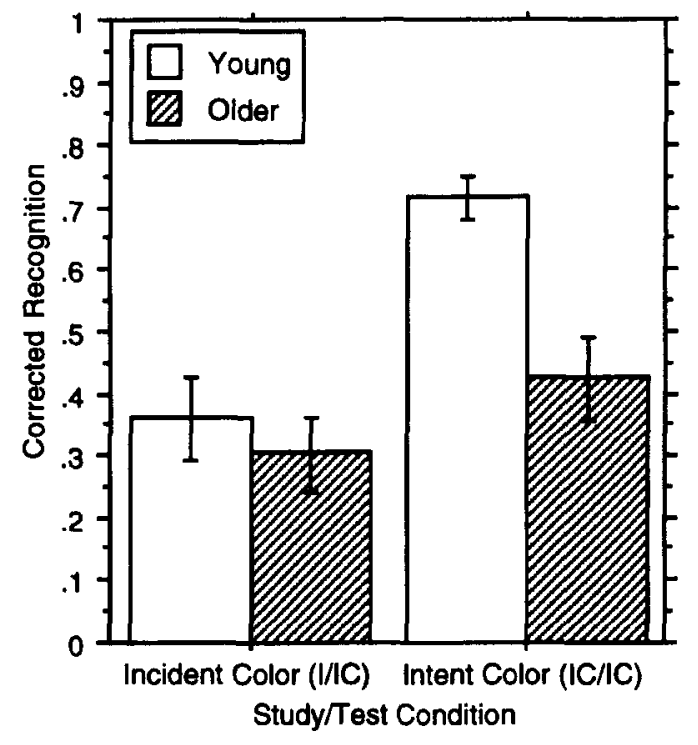

Figure 7. Mean corrected recognition performance and standard errors in Experiment $3 \mathrm{~B}$ binding conditions.

rately remember the individual item and color features would not aid performance on this test.

A 2 (age) $\times 2$ (binding condition) ANOVA on corrected recognition demonstrated that older adults' memory for bound item and color $(M=.37)$ was poorer than that of young adults $(M=.54)\left[F(1,60)=10.20, M S_{\mathrm{e}}=\right.$ $.05]$. There was also a significant effect of condition $[F(1,60)=18.79]$, where memory for bound item and color was poorer after incidental color encoding $(M=$ .33) than after intentional item and color encoding $(M=$ .57). This pattern was true for both young and older adults, and, given Hasher and Zacks's (1979) definition of automaticity, these results suggest that color information is not encoded automatically with item information by either age group. This conclusion is consistent with other investigations concerning the impact of encoding instructions on memory for the color of items (e.g., Light \& Berger, 1974; Light, Berger, \& Bardales, 1975; Park \& Mason, 1982; but see Ellis \& Rickard, 1989, for a different conclusion). There was also a reliable interaction between age and condition $[F(1,60)=4.70]$. From Figure 7 we note that the difference between young and older adults' memory for bound item and color was greater following intentional acquisition than following incidental acquisition. Indeed, the difference in the performance of young $(M=.36)$ and older $(M=.31)$ adults in the incidental encoding condition was not reliable $[F(1,30)<1]$, whereas older adults' corrected recognition performance $(M=.43)$ was significantly poorer than that of young adults $(M=.72)$ under intentional encoding instructions $\left[F(1,30)=16.25, M S_{\mathrm{e}}=.04\right]$. These results indicate that older adults are less able to bind together item and color, especially when information is acquired intentionally.

To summarize, older adults have intentional individual item and color feature recognition memory that is equiv- alent to young adults' under the conditions of the present experiment. Despite older adults' intact memory for separate item and color information, their recognition memory for bound item and color information is impaired relative to young adults', especially when encoding is intentional. The recognition test used here provides clear evidence that it is in fact a binding deficit that disrupts their performance- the only difference between targets and distractors occurred in how the item and color information was paired. It is important to note that the general pattern of young and older adults' performance in Experiment 3B was similar to their performance in Experiments $1 \mathrm{~B}$ and 2 . That is, the recognition tests used previously evidently provided a reasonable estimate of young and older adults' memory for bound information insofar as their performance in the previous experiments was similar to their performance in Experiment 3B.

\section{GENERAL DISCUSSION}

Taken together, these studies suggest that older adults have two separable deficits that contribute to their complex event memory impairments. First, not all feature memory is equally disrupted with aging; rather, the deficit is more selective. Older adults' feature memory for location was impaired (Experiment 1A), whereas their feature memory for item and for color was equivalent to that of young adults (Experiments $1 \mathrm{~A}$ and $3 \mathrm{~A}$ ). Second, memory for bound features appears to be impaired with aging. Older adults' memory for bound item and location information and bound item and color information was impaired (Experiments 1B, 2, and 3B). Older adults' impairment in binding was especially clear in the case of bound item and color (Experiments 1B, 2, and 3B), because older adults had intact memory for both features individually (Experiments $1 \mathrm{~A}$ and $3 \mathrm{~A}$ ).

Our results indicated that older adults' recognition memory for color features was intact. In contrast, Park and Puglisi (1985) reported that older adults had impaired color memory. Park and Puglisi tested subjects' memory for the colors of words and objects by presenting a black-and-white version of the word or object for recognition and, if subjects recognized the item, asking them to then circle the name of the color of the item (from a list of four). The method that we used to assess color memory differs significantly from their method: First, we tested color feature memory independently of memory for the items. Second, our methods required recognition of colors themselves, whereas Park and Puglisi's subjects indicated recognition of color names. Third, during the encoding phase, our subjects were directed to study color only; Park and Puglisi's intentional encoding instructions directed subjects to study both the items and their colors. The method used by Park and Puglisi to assess color memory more closely resembles our item \& color study/test condition than our color-only feature condition. Indeed, older adults performed more poorly than young adults on a recognition test of item $\&$ color after studying item $\&$ color in both Experiments $1 \mathrm{~B}\left(M_{\text {young }}=\right.$ 
$\left..65, M_{\text {older }}=.51\right)$ and $3 \mathrm{~B}\left(M_{\text {young }}=.71, M_{\text {older }}=.43\right)$, just as Park and Puglisi found. Given the results of the experiments presented here, Park and Puglisi's data may not reflect a deficit in memory for color per se, but rather an impairment in older adults' ability to bind item and color information together.

Experiment 3B showed that for both young and older adults, recognition memory for item and color improved when both features were encoded intentionally. Hasher and Zacks (1979) suggested that information that is common in the environment and is ubiquitously useful is often encoded with item information automatically. By Hasher and Zacks's definition, when information is automatically encoded, intentional acquisition of the information should not improve memory for it relative to incidental acquisition. Given the results here, apparently color information is not encoded automatically when item information is encoded.

Despite the fact that both groups profited from intentional acquisition, Experiment 3B showed that older adults' memory for bound items and colors was particularly impaired following intentional acquisition of the information. A similar pattern was also observed across experiments: older adults showed poor memory for item and color when acquisition was intentional (Experiment 1B) but less of a deficit when acquisition was incidental (Experiment 2). Older adults clearly have a deficit in binding with intentional encoding instructions, but it would be premature to conclude that older adults do not have a binding deficit with incidental encoding instructions. First, older adults tended to have a binding deficit under incidental encoding instructions in Experiment 2, and numerically, there was also a difference between young and older adults' performance in Experiment 3B. Second, the literature on age-related differences in memory following incidental and intentional encoding suggests that the question is not yet resolved. As we found here, some evidence suggests that age differences are larger under intentional encoding conditions (e.g., Park et al., 1982), and Spencer and Raz's (1995) meta-analysis of the literature on aging and contextual memory also suggests that age differences are larger with intentional acquisition. On the other hand, other data actually suggest that age differences are larger under incidental encoding conditions (e.g., Light \& Zelinski, 1983; Park et al., 1983; Uttl \& Graf, 1993, Experiment 2), and Uttl and Graf's (1993) review of the literature on incidental versus intentional encoding of location information suggested that this might be a consistent trend. Still other researchers have found that age differences are equivalent under incidental and intentional acquisition (e.g., Naveh-Benjamin, 1987, 1988; Uttl \& Graf, 1993, Experiment 1). In short, our data suggest that, at least for memory for items and their colors, the age-related differences in recognition memory are more dramatic under intentional than under incidental encoding conditions. However, given the inconsistency of the findings in the literature, some work remains to be done in order to establish the con- ditions that determine relative age differences under incidental or intentional encoding instructions.

Finding that not all memory for features was impaired and that binding of different types of information showed general age-related changes confirms the utility of making a distinction between the contributions of a feature deficit and a binding deficit to older adults' impaired complex event memory. In turn, it is likely that many of the documented "feature" memory deficits in older adults (see, e.g., Light \& Zelinski, 1983; Naveh-Benjamin, 1987, 1988; Park \& Puglisi, 1985; Park et al., 1982; Park et al., 1983; Perlmutter et al., 1981; Pezdek, 1983; Zelinski \& Light, 1988) may arise as a consequence of a binding deficit rather than (or in addition to) a feature deficit per se.

At this point, it is important to note that for methodological and analytic convenience, we have talked as if feature memory and binding are two entirely separate endeavors. However, item feature memory itself, for example, likely depends on binding item information to other aspects of the general experimental context. That is, information from the general experimental context, such as temporal information, location information, and so forth, is necessary to support the old/new judgments required by the feature recognition tests. It is more than likely that any dramatic impairment in binding will not only impair memory for bound features, but also impair memory for the features themselves to some degree. Moreover, binding, as it has been investigated here, has only been between items and some other feature (i.e., location, color). We suspect, however, that the same cognitive processes that are important for binding items to locations and items to colors are also important for binding items to other items, or all features into complex memories (Johnson, 1992; Johnson \& Chalfonte, 1994).

\section{The Concept of Memory for Features}

Not only have we made a distinction between feature memory and binding, we have also suggested that there may be a distinction between different kinds of features. Although we have referred to both item information and source-specifying information by the "neutral" term features, the human aging literature has adopted the notion that there are fundamental differences between item information and source information, or between content and context (e.g., Spencer \& Raz, 1995). Within memory for complex events, features constituting the memory that are of central interest are often considered "content" and features that are more peripheral are considered "context." Some researchers (e.g., Light \& LaVoie, 1993; Light \& Singh, 1987; McIntyre \& Craik, 1987) have suggested that there may be a specific age-related deficit in memory for context. Older adults are not as good at recollecting the sources of information that are presented, for example, in different perceptual or type modalities or in a male or female voice (e.g., Kausler, 1994; Light, 1991). How are we to distinguish context features from content features? Older adults' deficits in 
memory for individual features (i.e., location) may exist whether such features serve a central or peripheral role in a given event.

One might be inclined to adopt the working assumption that information that subjects are directed to study represents "content," whereas information that subjects do not study is "context." This approach was taken, for example, by Denney and her colleagues (Denney, Miller, Dew, \& Levav, 1991) in addressing the issue of age-related declines in context memory. They defined target or content information as the information that subjects were instructed to learn (word, landscape or border background, or both word and background) and context information as information present that subjects were not instructed to learn. However, using encoding focus to determine content and context yields a definition of context that is inconsistent with other aspects of the aging and memory literature, and with other human and nonhuman memory literatures as well.

Consider that in studies of encoding specificity and aging (e.g., Park, Puglisi, Smith, \& Dudley, 1987; Park et al., 1984; Puglisi, Park, Smith, \& Dudley, 1988), subjects were directed to study both the target and the "context" information or were more globally instructed to study all the information at hand, without excluding any specific information. Some information was considered "context" despite the fact that subjects were directed to study that information in addition to the target information (e.g., Puglisi et al., 1988). In this case, the focus of encoding did not determine what was defined as content and as context. Likewise, in the human amnesia literature, certain features are considered "context" despite being the focus of encoding at times (e.g., Mayes, 1992; Mayes, Meudell, \& Pickering, 1985). And for infants and nonhuman animals, where focus cannot be easily directed with verbal instructions, context is defined by what the experimenter views as the less salient or less predictive aspects of the experimental situation (e.g., Penick \& Solomon, 1991; Phillips \& LeDoux, 1992; Rovee-Collier, 1991).

Although it may seem intuitively unappealing, defining context on the basis of the experimenter's focus (rather than the subject's) may be the only way in which the term "context" can be used consistently. Moreover, this is probably the more common way of defining context, given the term's use in previous aging studies, in studies of human amnesia, and in studies of the role of context in classical conditioning in animals. Once this distinction has been made, researchers can then elaborate on particular parameters of their definitions of context, such as the relations between content and context (e.g., interactive, independent) or the different types of context (e.g., intraitem, extraitem) (e.g., Baddeley, 1982; Bjork \& Richardson-Klavehn, 1989). Although the experimenter may make some distinction between features, there is no a priori reason to assume that a similar distinction is made in the way in which features are processed.

\section{The Concept of Binding in Memory}

We have not yet elaborated the concept of binding other than to suggest that binding is responsible for the phenomenal experience of particular features being remembered as "belonging together." Theoretically, there are at least two ways in which the binding between features may be expressed: In one case, features may remain independently represented, but associated. In the other, features may be bound to form a new, conjoined representation that is uniquely different from the two features separately. Other researchers have alluded to similar distinctions in the way that information can be represented (e.g., Eichenbaum, 1994; Graf \& Schacter, 1989; Jacoby \& Brooks, 1984). Although binding may be represented in at least one of two ways, in the discussion of the present experiments, we have not distinguished between these different types of binding; the experiments presented here were not designed to do so. Thus, although we can suggest that binding is impaired as a consequence of age, we cannot say what type of binding is disrupted. Both types of binding may be disrupted, or one type may be more disrupted than the other, but only systematic investigations of age-related changes in binding will speak to this issue.

Another central issue is the relationship of memory for individual features to memory for bound features. In the present experiments, memory for individual features did not "limit" memory for bound information that included those features. In Experiment 3B, for example, young adults' recognition memory for item features was $91 \%$ and their memory for color features was $23 \%$. If levels of feature memory set an upper limit for bound memory performance, then young adults' recognition memory for bound item and color should not have exceeded $23 \%$. In contrast, young adults' actual recognition memory for bound item and color was $72 \%$. What must be recognized is that different encoding conditions (i.e., remember individual features, remember bound features) may yield different representations of the information. If features are bound, it may be difficult to access memory for the individual features, and this will result in poor feature memory performance, even though memory for the bound information, which includes these very features, will be accessed easily, resulting in bound memory performance that is quite good. When information is bound together, individual feature information may be less available, especially if the bound information is represented in a new, unitary, gestalt-like representation.

What might underlie the age-related changes in binding observed in the present experiments? One possibility is that older adults may be especially sensitive to the relatedness of features. In the experiments presented here, items and their locations and colors were not meaningfully related. For example, a leaf might appear in a shade of pink but not in a meaningfully related shade of green or brown. Likewise, a car might be located above a tree but not in a meaningful location such as next to a house. If it is easier for young adults to remember items in unrelated colors and locations than it is for older adults, then 
"hypersensitivity" to the relatedness of features might cause the apparent binding deficit in older adults, and if features were paired in a more meaningful way, the deficit might disappear.

Uttl and Graf's (1993) review of the literature on older adults' memory for spatial location provides some insight into this issue. Their analysis revealed that in "reallife" situations, older adults remember $93 \%$ of the spatial locations of objects that young adults remembered. In contrast, older adults remembered only $65 \%$ of the matrix-located or $61 \%$ of map-located objects that young adults remembered. However, Uttl and Graf empirically demonstrated that there was a significant age-related impairment even in memory for the spatial location of objects in real-life situations. In general, we suspect that the meaningfulness of the relationship between items and their locations or colors affects the ease with which these features are bound and recollected by both young and older adults. Recollection of bound, related features is likely to be due both to memory for associated features and to inferences about which features "belong together" (see Uttl \& Graf, 1993, Experiment 2 baseline data). For example, if subjects learn objects and colors that are meaningfully related, even when they cannot recollect that an apple was red, they may be able to infer that information; correct recollection may be a result of both specific memory influences and inferences from general knowledge about related features. In contrast, if subjects learn objects and colors that are not meaningfully related, correct recollection cannot be based on inferred feature information. In the experiments presented here, correct recollection of objects and their locations or colors cannot be due to inferences made about which features "go together." More generally, we do not suspect that greater sensitivity to the relatedness of features underlies older adults' binding deficit.

Evidently, older adults have an impairment in a particular cognitive process that is fundamental to binding. Reactivation is one cognitive process that operates on information that is no longer active; it is a mechanism by which information is brought back to a more "active state" (Johnson \& Hirst, 1991, 1993). By bringing information back, reactivation acts as an internally generated repetition of the information. If features must be cognitively co-active to be bound together, then reactivating prior feature information increases the probability that this information will be bound with other active information. Moreover, repetition via reactivation can increase the strength between already-bound features. Reactivation therefore serves a dual role: to promote opportunities for binding and to strengthen existing relations. The more a particular cognitive task requires reactivation (in either capacity), the worse the memory deficit should be if reactivation is disrupted (a more extensive discussion of reactivation and memory can be found in Johnson \& Chalfonte, 1994). We have further postulated that a cortico-hippocampal circuit may play an important role in reactivation and therefore in binding. Given that aging significantly affects the hippocampus and surrounding regions (e.g., Davis \& Bernstein, 1992; Powers, 1994; Selkoe, 1992; but cf. Raz, Torres, Spencer, \& Acker, 1993), reactivation may be impaired, producing negative consequences for older adults' ability to bind information together. The binding that occurs when features are intentionally encoded may be especially impaired if frontal lobe functioning is disrupted as well. The frontal lobes have been implicated in the initiation and control of reactivation processing (e.g., Stuss \& Benson, 1986), and encoding information intentionally may require more controlled reactivation than does incidental acquisition. Consistent with this, evidence suggests that aging affects frontal as well as hippocampal systems (e.g., Craik, Morris, Morris, \& Loewen, 1990; but cf. Johnson, De Leonardis, Hashtroudi, \& Ferguson, 1995).

A domain that is most likely influenced by both feature and binding deficits is source monitoring. Intact memory for features plays a crucial role in source monitoring (Johnson et al., 1993; Johnson \& Raye, 1981), because it is this feature information that specifies source. Intact binding processes are critical for developing the associations that correctly relate these source-specifying features within complex memories. A disruption in any of the binding processes or in the source-specifying, feature information will have deleterious consequences for source monitoring. Hashtroudi et al. (1989) and Ferguson et al. (1992) found that under certain conditions, older adults make less accurate source monitoring decisions than young adults. The results from the experiments presented here support the idea that older adults' poorer memory for location information and their disrupted binding processes contribute to their source monitoring deficits. Moreover, Hashtroudi et al. (1994) found that changing the focus that subjects adopt when processing information to one that increases the likelihood that features will be bound together decreases the source monitoring deficit noted in older adults. The cognitive processes important for integrating various aspects of source into complex memories are presumably the same processes that are important for binding together features; older adults have a disruption in feature memory and binding that affects tasks such as these.

\section{Conclusions}

In summary, two main findings emerged from these experiments: First, older adults did not demonstrate equally poor memory for all features; older adults showed a specific and disproportionate deficit in memory for location in contrast to their memory for item and for color, which was equivalent to that of young adults. Relevant neurophysiological evidence suggests that the hippocampus and adjacent entorhinal and parahippocampal cortical areas show significant age-related changes in humans (e.g., Davis \& Bernstein, 1992; Powers, 1994; Selkoe, 1992) that are important, considering that the hippocampus has been critically implicated in the computation and storage of spatial location information (O'Keefe \& Nadel, 1978). Thus, it is not entirely surprising that older adults may have a disproportionate deficit in memory for 
spatial location. Second, older adults demonstrated difficulty in binding features together (i.e., item and location, item and color). These feature and binding deficits may separately contribute to what has been described as older adults' context or source memory impairments. We have proposed that reactivation, a process that is important for binding together and strengthening aspects of memory, may be impaired in aging. The consequences of age-impaired reactivation and binding should be evident across a range of memory paradigms and systems. The binding account discussed here suggests that there will be consequences that are profound for all of memory, cutting across distinctions made in other accounts of age-related changes in memory.

\section{REFERENCES}

Baddeley, A. D. (1982). Domains of recollection. Psychological Review, 89, 708-729.

Bjork, R. A., \& Richardson-KLavehn, A. (1989). On the puzzling relationship between environmental context and human memory. In C. Izawa, (Ed.), Current issues in cognitive processes: The Tulane Floweree Symposium on Cognition (pp. 313-334). Hillsdale, NJ: Erlbaum.

Chapman, L. J., \& Chapman, J. P. (1973). Problems in the measurement of cognitive deficit. Psychological Bulletin, 79. 380-385.

Cralk, F. I. M. (1977). Age difference in human memory. In J. E. Birren \& K. W. Schaie (Eds.), Handbook of the psychology of aging (pp. 384-420). New York: Van Nostrand Reinhold.

Craik, F. I. M., \& MCDowd, J. M. (1987). Age differences in recall and recognition. Journal of Experimental Psychology: Learning. Memory \& Cognition, 13, 474-479.

Craik, F. I. M., Morris, L. W., Morris, R. G., \& Loewen, E. R. (1990). Relations between source amnesia and frontal lobe functioning in older adults. Psychology \& Aging, 5, 148-151.

Davis, H. P., \& Bernstein. P. A. (1992). Age-related changes in explicit and implicit memory. In L. R. Squire \& N. Butters (Eds.), Neuropsychology of memory (2nd ed., pp. 249-261). New York: Guilford.

Denney, N. W., Miller, B. V., Dew, J. R., \& Levav, A. L. (1991). An adult developmental study of contextual memory. Journal of Gerontologv, 46, 44-50.

DONALDSON, W. (1992). Measuring recognition memory. Journal of Experimental Psychology: General, 121, 275-277.

Eichenbaum, H. (1994, July). The hippocampus and declarative memory in humans and animals. Paper presented at the 6th annual meeting of the American Psychological Society, Washington. DC.

Ellis, N. R., \& Rickard, T. C. (1989). The retention of automatically and effortfully encoded stimulus attributes. Bulletin of the Psychonomic Societv, 27, 299-302.

Ferguson, S. A., Hashtroudi, S., \& Johnson, M. K. (1992). Age differences in using source-relevant cues. Psychology \& Aging. 7. $443-452$

GRAF, P., \& Schacter, D. L. (1989). Unitization and grouping mediate dissociations in memory for new associations. Journal of Experimental Psvchology: Learning, Memorv, \& Cognition, 15, 930940.

Gronlund, S. D. \& RatclifF. R. (1989). Time course of item and associative information: Implications for global memory models. Journal of Experimental Psychology: Learning, Memory, \& Cognition, 15, 846-858

HASHER, L., \& ZACKS, R. T. (1979). Automatic and effortful processes in memory. Journal of Experimental Psvchologv: General, 108, 356-388.

Hashtroudi, S., Johnson, M. K., \& Chrosniak, L. D. (1989). Aging and source monitoring. Psychology \& Aging, 4, 106-112

Hashtroudi, S., Johnson, M. K., Vnek, N., \& Ferguson, S. A.
(1994). Aging and the effects of affective and factual focus on source monitoring and recall. Psychology \& Aging, 9, 160-170.

HUMPHREYS, M. S. (1976). Relational information and the context effect in recognition memory. Memory \& Cognition, 4, 221-232.

HUMPHREYS, M. S. (1978). Item and relational information: A case for context independent retrieval. Journal of Verbal Learning \& Verbal Behavior, 17, 175-187.

JACOBY, L. L., \& BRoOKs, L. R. (1984). Nonanalytic cognition: Memory, perception, and concept learning. In G. H. Bower (Ed.), The psychology of learning and motivation: Advances in research and theory (Vol. 18, pp. 1-47). New York: Academic Press.

JoHNSON, M. K. (1992). MEM: Mechanisms of recollection. Journal of Cognitive Neuroscience, 4, 268-280.

Johnson, M. K., \& Chalfonte, B. L. (1994). Binding complex memories: The role of reactivation and the hippocampus. In D. L. Schacter \& E. Tulving (Eds.), Memory systems 1994 (pp. 311 -350). Cambridge, MA: MIT Press.

Johnson, M. K., De Leonardis, D. M., Hashtroudi, S., \& Ferguson, S. A. (1995). Aging and single versus multiple cues in source monitoring. Psychology \& Aging, 10, 507-517.

Johnson, M. K., Hashtroudi, S., \& Lindsay, D. S. (1993). Source monitoring. Psychological Bulletin, 114, 3-28.

JoHnSON, M. K., \& HiRST, W. (1991). Processing subsystems of memory. In R. G. Lister \& H. J. Weingartner (Eds.), Perspectives on cognitive neuroscience (pp. 197-217). New York: Oxford University Press.

Johnson, M. K., \& Hirst, W. (1993). MEM: Memory subsystems as processes. In A. Collins, M. Conway, S. Gathercole, \& P. Morris (Eds.), Theories of memory (pp. 241-286). Hove, U.K.: Erlbaum.

Johnson, M. K., \& RAYE, C. L. (1981). Reality monitoring. Psychological Review, 88, 67-85.

KAUSLER, D. H. (1994). Learning and memory in normal aging. San Diego: Academic Press.

Kausler, D. H., \& PuCKeTt, J. M. (1981). Adult age differences in memory for sex of voice. Journal of Gerontology, 36, 44-50.

LiGHT, L. L. (1991). Memory and aging: Four hypotheses in search of data. Annual Review of Psychology, 42, 333-376.

LIGHT, L. L., \& BERGER, D. E. (1974). Memory for modality: Withinmodality discrimination is not automatic. Journal of Experimental Psychology, 103, 854-860.

Light, L. L., Berger, D. E., \& Bardales, M. (1975). Trade-off between memory for verbal items and their visual attributes. Journal of Experimental Psychology: Human Learning \& Memory, 104, 188-193.

Light, L. L., \& LAVoie, D. (1993). Direct and indirect measures of memory in old age. In P. Graf \& M. E. J. Masson (Eds.), Implicit memory: New directions in cognition, development, and neuropsychology (pp. 207-230). Hillsdale, NJ: Erlbaum

LigHT, L. L., \& SiNGH, A. (1987). Implicit and explicit memory in young and older adults. Journal of Experimental Psychology: Learning, Memory, \& Cognition, 13, 531-541

LigHT, L. L., \& ZELINSKI, E. M. (1983). Memory for spatial information in young and old adults. Developmental Psychology, 19, 901-906.

MAYES, A. R. (1992). What are the functional deficits that underlie amnesia? In L. R. Squire \& N. Butters (Eds.), Neuropsychology of memory (2nd ed., pp. 23-35). New York: Guilford.

Mayes, A. R, Meudell, P., \& Pickering, A. (1985). Is organic amnesia caused by a selective deficit in remembering contextual information" Corter, 21, 167-202.

MCINTYRE, J. S., \& CRAIK, F. I. M. (1987). Age differences in memory for item and source information. Canadian Journal of Psychology, 41, 175-192

NAVEH-BenJamin, M. (1987). Coding of spatial location information: An automatic process? Journal of Experimental Psychologv: Learning, Memorv. \& Cognition, 13, 595-605.

NAVEH-Beniamin, M. (1988). Recognition memory of spatial location information: Another failure to support automaticity. Memory \& Cognition, 16, 437-445

O'KEEFE, J., \& NADEL, L. (1978). The hippocampus as a cognitive map. London: Oxford University Press. 
Park, D. C., Cherry, K. E., Smith, A. D., \& Lafronza, V. N. (1990) Effects of distinctive context on memory for objects and their locations in young and elderly adults. Psychology \& Aging, 5, 250-255.

PARK, D. C., \& MASON, D. A. (1982). Is there evidence for automatic processing of spatial and color attributes present in pictures and words? Memory \& Cognition, 10, 76-81.

PARK, D. C., \& PUGLisi, J. T. (1985). Older adults' memory for the color of pictures and words. Journal of Gerontology, 40, 198-204.

Park, D. C., Puglisi, J. T., \& Lutz, R. (1982). Spatial memory in older adults: Effects of intentionality. Journal of Gerontology, 37, 330335.

Park, D. C., Puglisi, J. T., Smith, A. D., \& Dudley, W. N. (1987). Cue utilization and encoding specificity in picture recognition by older adults. Journal of Gerontology, 42, 423-425.

Park, D. C., Puglisi, J. T., \& Sovacool, M. (1983). Memory for pictures, words, and spatial location in older adults: Evidence for pictorial superiority. Journal of Gerontology, 38, 582-588.

Park, D. C., Puglisi, J. T., \& Sovacool, M. (1984). Picture memory in older adults: Effects of contextual detail at encoding and retrieval. Journal of Gerontology, 39, 213-215.

Penick, S., \& Solomon, P. R. (1991). Hippocampus, context, and conditioning. Behavioral Neuroscience, 105, 611-617.

Perlmutter, M., Metzger, R., Nezworski, T., \& Miller, K. (1981). Spatial and temporal memory in 20 and 60 year olds. Journal of Gerontology, 36, 59-65.

Pezdek, K. (1983). Memory for items and their spatial locations by young and elderly adults. Developmental Psychology, 19, 895-900.

PhIL.LIPS, R. G., \& LeDoux, J. E. (1992). Differential contribution of amygdala and hippocampus to cued and contextual fear conditioning. Behavioral Neuroscience, 106, 274-285.

Powers, R. E. (1994). Neurobiology of aging. In C. E. Coffey \& J. L. Cummings (Eds.), Textbook of geriatric neuropsychiatry (pp. 35 69). Washington, DC: American Psychiatric Press.

Puglisi, J. T., PARK, D. C., Smith, A. D., \& Dudley, W. N. (1988). Age differences in encoding specificity. Journal of Gerontology, 43, 145-150.

Raz, N., Torres, I. J., Spencer, W. D., \& Acker, J. D. (1993). Pathoclysis in aging human cerebral cortex: Evidence from in vivo MRI morphometry. Psychobiology, 21, 151-160.

ROVEE-COLlier, C. (1991). The "memory system" of prelinguistic infants. In A. Diamond (Ed.), Development and neural bases of higher cognitive functions (Annals of the New York Academy of Sciences, Vol. 608, pp. 517-542). New York: New York Academy of Sciences.

SChacter, D. L., KazNiak, A. K., Kinlstrom, J. F., \& VAldiserri, M. (1991). On the relationship between source monitoring and aging. Psychology \& Aging, 6, 559-568.

SCHEAR, J. M., \& NEBES, R. D. (1980). Memory for verbal and spatial information as a function of age. Experimental Aging Research, 6, 271-281.

SELKOE, D. J. (1992, September). Aging brain, aging mind. Scientific American, 267, 135-142.

SNOdGRass, J. G., \& VANDERWART, M. (1980). A standardized set of 260 pictures: Norms for name agreement, image agreement, familiarity, and visual complexity. Journal of Experimental Psychology: Human Learning \& Memory, 6, 174-215.

SPENCER, W. D., \& RAZ, N. (1995). Differential effects of aging on memory for content and context: A meta-analysis. Psychology \& Aging, 10, 527-539.

Stuss, D. T., \& Benson, D. F. (1986). The frontal lobes. New York: Raven Press.

UtTL, B., \& GRaF, P. (1993). Episodic spatial memory in adulthood. Psychology \& Aging, 8, 257-273.

ZELINSKI, E. M., \& LIGHT, L. L. (1988). Young and older adults' use of context in spatial memory. Psychology \& Aging, 3, 99-101.

\section{NOTES}

1. WAIS-R vocabulary scores were not available for the young subjects in Experiments 1 or 2. However, in other experiments drawn from the same Princeton student population (e.g., Experiments $3 \mathrm{~A}$ and 3B), the average WAIS-R score was about 21.6 for the young adults.

2. Target items, locations, and colors were successfully identified in a two-alternative forced choice matching task at very high levels (items, $100 \%$; locations, $100 \%$; colors, $98 \%$ ), thus documenting the visual discriminability of the features. None of the subjects from this pretesting participated in the experiments reported here.

3 . The $p$ values for corrected recognition and $A^{\prime}$ scores, respectively, were as follows: Experiment $1 \mathrm{~A}, p<.05, p<.06$; Experiment $1 \mathrm{~B}, p<.05, p<.06$; Experiment $2, p<.06, p<.05$. The analyses of $A^{\prime}$ scores in all other instances yielded the same outcome as did the analyses of corrected recognition scores.

\section{APPENDIX}

The following is a list of RGB values that describe the colors used in the stimuli of Experiments 1-3. We used color laser prints of the stimuli that were colored on a Macintosh IIci in the graphics environment of PowerPoint (Version 2.01; Microsoft).

\begin{tabular}{|c|c|c|c|}
\hline \multirow[b]{2}{*}{ Stimulus } & \multicolumn{3}{|c|}{ Colors } \\
\hline & $\mathrm{R}$ & $\mathrm{G}$ & B \\
\hline 1 & 0 & 44564 & 0 \\
\hline 2 & 0 & 57146 & 51903 \\
\hline 3 & 0 & 65535 & 0 \\
\hline 4 & 1951 & 39640 & 55154 \\
\hline 5 & 13107 & 25952 & 64486 \\
\hline 6 & 16253 & 0 & 2884 \\
\hline 7 & 17301 & 36437 & 0 \\
\hline 8 & 19660 & 11796 & 0 \\
\hline 9 & 20185 & 20447 & 0 \\
\hline 10 & 20709 & 0 & 37748 \\
\hline 11 & 24903 & 36699 & 65010 \\
\hline 12 & 28311 & 0 & 17301 \\
\hline 13 & 29097 & 17563 & 0 \\
\hline 14 & 35127 & 262 & 62389 \\
\hline 15 & 35913 & 62651 & 60030 \\
\hline 16 & 41680 & 49544 & 65273 \\
\hline 17 & 41680 & 65535 & 41942 \\
\hline 18 & 44268 & 180 & 7167 \\
\hline 19 & 45874 & 47447 & 0 \\
\hline 20 & 46399 & 0 & 27000 \\
\hline 21 & 46923 & 24641 & 63962 \\
\hline 22 & 54525 & 40894 & 65535 \\
\hline 23 & 56098 & 65535 & 47185 \\
\hline 24 & 58719 & 16515 & 23855 \\
\hline 25 & 61340 & 37224 & 0 \\
\hline 26 & 63962 & 23068 & 46923 \\
\hline 27 & 64748 & 262 & 10486 \\
\hline 28 & 65535 & 20709 & 2097 \\
\hline 29 & 65535 & 41680 & 31981 \\
\hline 30 & 65535 & 50593 & 53214 \\
\hline
\end{tabular}

(Manuscript received February 3, 1995: revision accepted for publication May 17, 1995.) 